\title{
Physical activity throughout adolescence and body composition at 18 years: 1993 Pelotas (Brazil) birth cohort study
}

Virgílio Viana Ramires ${ }^{1 *}$, Samuel Carvalho Dumith², Fernando Cesar Wehrmeister ${ }^{1}$, Pedro Curi Hallal ${ }^{1}$, Ana Maria Baptista Menezes ${ }^{1}$ and Helen Gonçalves ${ }^{1}$

\begin{abstract}
Background: Adolescence is a period of accelerated development and increases in body composition. Physical activity (PA) practice has been associated with the development of major components of body composition (bone, muscle and fat). However, the longitudinal effects of PA of different intensities during adolescence are still not well understood. Thus, the main goal this study has investigate the association between practice of moderate- and vigorous-intensity physical activity throughout adolescence and body composition, specifically lean mass (LM) and fat mass (FM), at age 18.
\end{abstract}

Methods: In this cohort study, physical activity was measured at 11, 15 and 18 years, using questionnaires. Thresholds of 300, 150 and 75 min per week, were used for MVPA, moderate- and vigorous-intensity physical activity, respectively. Consistent physical activity was defined as reaching the thresholds at the three followups. FM and LM at age 18 were assessed by DXA and expressed as fat mass (FMI) and lean mass (LMI) indexes. To verify the association between the trajectories of MVPA, moderate- and vigorous-intensity physical activity in adolescence and FM and LM at 18, multivariate analyses were performed through multiple linear regressions adjusted for co-variables.

Results: A total of 3,176 adolescents were evaluated. The consistent practice of moderate- and vigorousintensity physical activity according to thresholds during adolescence were directly related to the LMI in boys (moderate-intensity - $\beta=0.40$ and $\mathrm{C} 195 \% 0.13 ; 0.68$ and vigorous-intensity $-\beta=0.95$ and $\mathrm{C} 195 \% 0.69 ; 1.21$ ) and girls (Moderate-intensity $-\beta=0.23$ and Cl95\% 0.02; 0.45 and vigorous-intensity $-\beta=0.80$ and Cl95\% 0 . 29; 1.32). Practice of vigorous-intensity physical activity alone showed to be inversely associated with the FMI in boys $(\beta=-0.53$ and Cl95 \% -0.96;-0.10).

Conclusion: Consistent physical activity practice during adolescence was associated with greater lean mass in both sexes. In boys, vigorous-intensity physical activity was associated with less fat mass.

Keywords: Adolescents, Motor activity, Lean mass, Fat mass, Longitudinal studies

\footnotetext{
* Correspondence: virgilioramires@hotmail.com

${ }^{1}$ Graduate Program in Epidemiology, Federal University of Pelotas, Marechal

Deodoro, 1160 - 3 Piso, 96020-220 Pelotas, Rio Grande do Sul, Brazil

Full list of author information is available at the end of the article
} 


\section{Background}

Adolescence is characterized as a period of rapid body growth with important changes in body composition [1]. It is also when the body composition standards that tend to remain for life are established [2], which can reflect on the development of morbidities during adulthood [3]. Physical activity practice through adolescence has been associated with benefits in the development of bones [4], muscles [5], and body fat [6]. However, this period has also shown a decrease in the practice of physical activities [7].

The relationships between physical activity practice and adolescent's body composition have been widely studied. Nevertheless, fat mass (FM) and bone mass (BM) have received more attention [8, 9]. Less is known about the impact of physical activity on lean mass (LM). The few studies that aimed to investigate the relation between physical activity and LM in adolescents report a direct effect between the variables $[5,10,11]$. However, none of these studies isolated the effects of moderateand vigorous-intensity physical activity. Moreover, only one used a longitudinal study design [6]. Hence, there is no information on the benefits of different physical activities intensities during adolescence regarding LM in early adulthood, particularly with longitudinal data.

The association between physical activity and body fat (BF) has been widely studied since exercise is often recommended as an alternative to reduce weight and BF [12]. Recent findings with adolescents have indicated that physical activity is inversely associated with BF levels, especially moderate and vigorous exercise [13, 14]. Nonetheless, many of these studies employed a cross-sectional design and did not isolate the effects of moderate- and vigorous-intensity physical activities. Therefore, there is still little information regarding the specific effects of moderate- and vigorous-intensity physical activities on $\mathrm{BF}[15,16]$.

The present study aimed to investigate the association among consistent physical activity practice of moderate to vigorous intensity (MVPA), as well as, specifically the moderate- and vigorous intensity during adolescence (between 11 and 18 years old) on FM and LM at 18 years.

\section{Methods}

\section{Sample}

Pelotas is located in the extreme South of Brazil, with approximately 330.000 inhabitants. From January 1st up to December 31st, in the 1993 calendar year, all live births from mothers living at the urban area of the municipality were invited to participate in the birth cohort study. During childhood and adolescence, the 5.249 members of the birth cohort were followed several times. In the adolescence period, they were followed at
11,15 and 18, with follow-up rates of $87.5 \%, 85.7 \%$ and $81.3 \%$, respectively. Those who showed physical activity data for all three follow-ups in adolescence and body composition (FM and LM) at 18 years old, in addition to the co-variables used to adjust the analyzes were considered with valid data for this study. Detailed information on the cohort can be found in previous papers $[17,18]$. The variables used in the analysis of the present study are specified below.

\section{Body composition variables at $\mathbf{1 8}$ years old - outcome}

At 18 years old, standing height was measured with a wood and aluminum stadiometer with $0.1 \mathrm{~cm}$ precision. The weight was measured using a precision scale $(0.01 \mathrm{~kg})$. The FM and LM levels were measured through dual-energy $x$-ray absorptiometry using a DXA device (Lunar Prodigy, GE Healthcare, USA). This exam was performed with the adolescents in supine position and all metal accessories (earrings, body piercings, rings, etc.) were removed. Adolescents with metal orthopedic devices or who were pregnant did not undergo this exam. In the body composition measurements, the subjects wore light, tight spandex clothes (shorts and sleeveless shirt) and no shoes. All procedures were performed by a team previously trained to operate all equipment and carry out anthropometry.

Given the direct relation between FM and LM with the subjects' height, the authors chose to express these variables as fat-mass index (FMI) and lean-mass index (LMI) [19]. These indices were generated from the FM and LM readings from the DXA device. Since the total body weight informed by the DXA device comprises the sum of the fat, lean, and bone masses and since this weight does not equal the total body mass - measured with a precision scale -, FM and LM were adjusted to the total weight according to the following equations:

$$
\begin{aligned}
\text { LMadjusted } & =\frac{\mathrm{LM}}{\mathrm{TBM}_{\mathrm{DXA}}} \times \mathrm{TBM}_{\mathrm{M}} \text { and FMadjusted } \\
& =\frac{\mathrm{FM}}{\mathrm{TBM}_{\mathrm{DXA}}} \times \mathrm{TBM}_{\mathrm{M}} \text {, where }
\end{aligned}
$$

$\mathrm{FM}=$ fat mass $(\mathrm{kg}) ; \mathrm{LM}=$ lean mass $(\mathrm{kg}) ; \mathrm{TBM}_{\mathrm{DXA}}=$ total body mass $(\mathrm{kg})$, the sum of fat, lean, and bone masses $(\mathrm{kg})$ provided by the DXA device; and $\mathrm{TBM}_{\mathrm{M}}=$ total body mass $(\mathrm{kg})$ measured.

After this procedure, the FM and LM variables were adjusted to the subjects' height with their respective indices according to the equations:

$$
\mathrm{FMI}=\frac{\text { FMadjusted }}{\mathrm{H}^{2}} \text { e LMI }=\frac{\text { LMadjusted }}{\mathrm{H}^{2}}, \text { where }
$$

FMI $=$ fat mass index $\left(\mathrm{kg} / \mathrm{m}^{2}\right) ; \mathrm{LMI}=$ lean mass index $\left(\mathrm{kg} / \mathrm{m}^{2}\right)$; and $\mathrm{H}=$ height $(\mathrm{m})$. 


\section{Physical activity variables - exposition}

Physical activity practice at 11,15 , and 18 years old was measured through questionnaires. At 11 and 15, the subjects were asked about how they commuted to school and about their leisure physical activities from a list of 13 activities (soccer, indoor soccer, track and field, basketball, dance, gymnastics, martial arts, swimming, volleyball, tennis/paddle, handball, dodgeball, and street cricket). The subjects could also report three activities not in the list. To each activity in the list, adolescents were asked if they did the activity and in case of a positive response, they were asked about the frequency of participation in these activities, in days per week, and then an average duration in minutes per participation. In order to adapt the instrument to the age group and local context, at 15, the modalities handball, dodgeball, and street cricket were replaced by hiking, weight lifting, and gym. The questionnaires may be accessed in (www.epidemio-ufpel.org.br). At 18, physical activity at leisure and commuting was inquired using the long version of the International Physical Activity Questionnaire (IPAQ) (www.ipaq.ki.se) [20].

The moderate- and vigorous physical activity score in each follow-up was tallied based on the sum of the time spent with leisure and commuting physical activity as follow.

From this list of leisure sports activities and the questions pertaining to the commute to school in the instruments used at 11 and 15 years old, the activities were classified as moderate and vigorous while observing the thresholds for physical activity intensity in metabolic equivalents (METs) - a unit used to estimate the metabolic cost of physical activities $(<3.0$ METs = light; $3.0-$ 6.0 METs = moderate, and $>6.0 \mathrm{METs}=$ vigorous $)$, proposed by Pate et al. (1995) [21]. Based on the physical activity compendium for adolescents created by Ridley et al. (2008) [22], the mean of three possible MET amounts spent for each modality was calculated while considering the possibility of light, moderate, and vigorous intensities. After the mean MET values were obtained for each modality in the instrument, they were classified as light, moderate, or vigorous-intensity. For example: According to the compendium for adolescents, handball can be practiced according to the following intensities, in METs: light $=6.0 \mathrm{METs}$, moderate $=8.0$ METs, and vigorous $=10$ METs. In this case, the average in METs of handball is 8.0 METs, thus it is classified as a vigorous-intensity activity.

The same procedure applied to the leisure activities was used to classify commuting, hiking, and cycling. For weight lifting, practiced at 15 years old, although it is a light-intensity activity [22], the authors chose to consider its energy expenditure in METs according to the compendium created for adults, hence it was classified as a moderate-intensity activity [23]. The reason for this choice is that, in the local context, this activity is usually practiced in gyms with moderate- and vigorous- intensity to develop muscle mass or achieve weight loss. At 18 years old, the leisure and commuting physical activities were classified and grouped into moderate- and vigorousintensity according to IPAQ's guidelines for processing and analysis [20].

After each activity have been classified according their intensity, variables of MVPA, moderate- and vigorousintensity physical activity were created in accordance to the time spend in minutes per week. The MVPA score was tallied based on the sum of the time spent with moderate- and vigorous physical activity.

In order to verify the relation between time practicing moderate- and vigorous-intensity physical activity at each age (11, 15, and 18 years old) and FM and LM at 18, time tertiles were used for each intensity. For the main analysis, trajectories of MVPA, moderate and vigorous intensity physical activity were created based on weekly minutes spent on each intensity at 11,15 and 18 years of age, as follows. Initially, the variables were dichotomized according to the time thresholds equal to or greater than 300,150 , and 75 min of weekly MVPA, moderate- and vigorous-intensity physical activity practice, respectively. The threshold to MVPA (300 $\mathrm{min} / \mathrm{w})$ was defined according to the recommendations. Thresholds for moderate and vigorous intensity physical activity in adolescents were not found. Thus, thresholds to moderate $(150 \mathrm{~min} / \mathrm{w})$ and vigorous $(75 \mathrm{~min} / \mathrm{w})$ intensity physical activity used in this study were defined based on a minimal energy expenditure of 13 MET-hours per week which is equivalent to walking $150 \mathrm{~min}$ per week at a 4 mile per hour pace or 75 min per week at a 6 mile per hour pace, representing moderate and vigorous intensity, respectively. The times and intensities mentioned above show a relationship with body composition parameters [24].

After dichotomization, variables were generated to describe the trajectories according to the thresholds above: has never reached, reached once, reached twice, and has always reached. In addition, time quartiles of moderateand vigorous intensity physical activity accumulated in the three follow-up periods were built from the sum of the minutes of moderate and vigorous-intensity physical activity. The reason to choose the variable of physical activity accumulated in quartiles was because it allows better view of the higher and lower groups of times of practice and dose-response effect.

\section{Co-variables}

A series of variables of the adolescents and their mothers that are independently related to physical activity practice or to FM and LM were selected to adjust the 
analyses for potential confounding factors. The variables from the adolescents were: Socioeconomic level, measured through the asset index (IEN) [25], expressed in quintiles; self-reported skin color (white, black, pardo [official term used in the Brazilian census, meaning dark-skinned], yellow, and Indian); continuous body mass index (BMI); screen time (TV, videogame, and computer) in hours per day; use of medicine for weightloss (yes or no); diet to weight-loss prescribed by physician or nutritionists (yes or no); high fat intake, obtained through the Block Fat Screener [26], expressed in high or low fat intake; all collected at 11 years old. In addition, sexual maturity stage of adolescents was selfreported at 15 through the Tanner scale for pubic hair [27]. The mother's variables were: schooling, in years of education completed; physical activity, in minutes per week (active $\geq 150 \mathrm{~min} /$ week); and continuous BMI, all collected at the 11-year-old follow-up.

\section{Statistical analyses}

The main characteristics of the sample are described as means and standard deviations for the continuous variables and as absolute and relative frequencies for the categorical variables. Bivariate analyses were performed by applying simple linear regressions to verify the raw association between the moderate- and vigorous-intensity physical activity variables, as well as the trajectories of MVPA, moderate- and vigorous-intensity physical activity with FM and LM at 18 years old. In order to verify the association between the trajectories of MVPA, moderate- and vigorous-intensity physical activity in adolescence and FM and LM at 18, multivariate analyses were performed by applying multiple linear regressions adjusted for covariables. Analyses stratified by sex were performed by considering the sexual dimorphism in the development of FM and LM $[1,28]$. The results of the regressions are presented as regression coefficients $(\boldsymbol{\beta})$ and their respective confidence intervals of $95 \%$ (CI95\%). Values of $p$ below 0.05 for differences between means or for linear trends were accepted as statistically significant. All analyses were carried out using the statistical package Stata version 12.1.

\section{Results}

The final sample analyzed in the present study was made up of 3.176 adolescents who had valid data for the exposition and outcome variables beyond the co-variables. Of these 1.637 (51.5\%) were female.

The demographics, physical activity, screen time, maturity and body composition data of adolescents are described in Table 1.

The distribution of the time spent with MVPA, moderate- and vigorous-intensity physical activity during adolescence is presented in Table 2. The time the boys spent per week with MVPA and vigorous-intensity physical activity was higher than the time spent by girls at 11, 15, and 18 years old. When moderate-intensity physical activity was considered, the girls' weekly time was higher than the boys' at 11 and 15, but the boys' was higher than the girls' at 18. Also, the percentage of boys who reached or exceeded the recommendations of MVPA practice for adolescents ( $\geq 300 \mathrm{~min} /$ week) was also higher than among the girls. Furthermore, the data show that both boys and girls increase physical activity during adolescence, especially the MVPA and moderate intensity physical activity in boys and girls and vigorous intensity physical activity in boys.

\section{Association between physical activity and FMI and LMI}

Table 3 shows the relations between tertiles of moderate- and vigorous-intensity physical at 11, 15, and 18 years old with FMI and LMI at 18 . The raw analyses showed inverse relations between FMI with vigorousintensity physical activity at 15 years old and moderateintensity physical activity at 18 for males only. In the analysis of the association between tertiles of moderateand vigorous-intensity physical activities and LMI, data showed that both are directly related to LMI for boys and girls at all 3 ages of follow-up, except for males at 11 years old (Table 3 ).

The relations between the MVPA, moderate- and vigorous-intensity physical activity trajectory with FMI and LMI for boys and girls are presented in Table 4. After the adjusted analyses between the physical activity trajectories and FMI, it was found that only the vigorous physical activity trajectory among boys was inversely related to FMI (adjusted $p$ value $=0.03$ ). When the relation between the MVPA, moderate- and vigorous-intensity physical activity trajectories during adolescence and LMI was tested, an important direct effect of physical activity on LM of 18-year-old for boys and girls was observed. Among boys, a dose-response effect could be observed for all physical activity trajectories in adjusted analysis. In girls, only the vigorous-intensity physical activity trajectory showed a dose-response effect among the categories analyzed (adjusted $p$ value $<0.001$ ).

The association between quartiles of minutes accumulated moderate- and vigorous-intensity physical activity at 11,15 , and 18 years old with FMI and LMI in boys and girls at 18 are showed in Fig. 1. No effect was observed between the accumulated time of moderate- and vigorous-intensity physical activity and FMI. When LMI was considered, a positive association was found between the accumulated time of moderate- and vigorousintensity physical activity and LMI at 18 years old, for boys and girls, with a dose-response effect observed in raw and adjusted analyses. The greatest magnitude of 
Table 1 Characteristics of the sample. The 1993 Pelotas (Brasil) Birth Cohort

\begin{tabular}{lll}
\hline Variables & Boys & Girls \\
& $\mathrm{n}(\%)$ & $\mathrm{n}(\%)$ \\
\hline
\end{tabular}

Skin color
Black
White
Brown
Yellow
Indigenous
Asset índex in quint
1st (poorest)
2nd
3rd
4rd

5 rd (richest)

Tanner stage (pubic hair)

1
2
3
4
5

MVPA 11,15 and $18 y$

( $\geq 300 \mathrm{~min} /$ week)

$\begin{array}{lll}\text { Has never reached } & 112(6.3) & 474(24.6) \\ \text { Reached once } & 391(21.9) & 741(38.5) \\ \text { Reached twice } & 725(40.5) & 544(28.3) \\ \text { Has always reached } & 559(31.3) & 164(8.6) \\ \text { Physical activity (moderate-intensity) } & & \\ \text { 11, 15 and 18y (>150 min/week) } & & \\ \text { Has never reached } & 190(10.5) & 219(11.3) \\ \text { Reached once } & 588(32.4) & 555(28.5) \\ \text { Reached twice } & 702(38.6) & 712(36.5) \\ \text { Has always reached } & 337(18.5) & 462(23.7) \\ \text { Physical activity (vigorous-intensity) } & & \\ \text { 11, 15 and 18y (>75 min/week) } & & 1.095(56.2) \\ \text { Has never reached } & 184(10.2) & 657(33.7) \\ \text { Reached once } & 436(24.1) & 173(8.9) \\ \text { Reached twice } & 696(38.4) & 24(1.2) \\ \text { Has always reached } & 495(27.3) & \\ \text { Screen time at 11y (hours/day) } & & 7.5(1.9) \\ \text { in tertiles - Mean (SD) } & & 4.3(0.6) \\ \text { Upper } & 7.7(2.2) & 1.9(0.9) \\ \text { Middle } & 4.3(0.5) & \\ \text { Bottom } & 1.9(0.9) & \end{array}$

Table 1 Characteristics of the sample. The 1993 Pelotas (Brasil) Birth Cohort (Continued)

Body mass index at $11 y$ in

tertiles - Mean (SD)

\begin{tabular}{cll} 
Upper & $22.6(3.0)$ & $22.6(3.0)$ \\
Middle & $17.7(0.8)$ & $17.8(0.8)$ \\
$\quad$ Bottom & $15.4(0.8)$ & $15.2(1.0)$ \\
Fat mass (kg) - Mean (SD) & $12.8(9.4)$ & $21.9(9.3)$ \\
Lean mass (kg) - Mean (SD) & $54.3(6.0)$ & $36.5(4.4)$ \\
Fat mass index at 18y - Mean (SD) & $4.2(3.0)$ & $8.4(3.6)$ \\
Lean mass index at 18y - Mean (SD) & $18.0(1.6)$ & $13.2(1.4)$ \\
\hline
\end{tabular}

MVPA Moderate to vigorous physical activity

the association on the LMI of boys and girls was observed for vigorous physical activity (Fig. 1).

\section{Discussion}

By investigating the longitudinal and cross-sectional association between physical activity practice during adolescence and body composition in early adulthood, particularly FM and LM, the main findings were: (i) physical activity practice increase in both sexes; (ii) boys and girls who practiced physical activity for more time at 11,15 , and 18 years old or who maintained physical activity practice MVPA, moderateand vigorous-intensity, according to the thresholds established, throughout adolescence had higher LM levels at 18 years old, with a greater effect promoted by vigorous physical activity; (iii) the consistent practice of vigorous physical activity during adolescence resulted in lower FM levels for boys at 18 years old; (iv) the age of 15 was when vigorous-intensity physical activity had the greatest impact on FM of boys at 18 .

It is common knowledge that the adolescence period is characterized by relevant decreases in physical activity [7]. On the other hand, the results from this study show an increase in physical activity practice for both sexes. Among boys, the most consistent increased was observed for MVPA, while for girls this increase was found for moderate physical activity. Although the results are surprising for this age group, other studies carried out with adolescents in Pelotas have also found similar results $[29,30]$. Regarding the increase in physical activity practice, we believe it may be the result of campaigns developed in the last few years promoting physical activity practice, as well as aspects related to the cult of a well-built body, a behavior which is very prevalent in this age group. As regard to the differences observed in the intensities of the practiced activities, we believe that such effects may be consequence of the types of activities more practiced by this age group in the local context, in which girls are more involved in activities such 
Table 2 MVPA, moderate and vigorous-intensity physical activity measured at 11, 15 and 18 years. The 1993 Pelotas (Brasil) Birth Cohort

\begin{tabular}{|c|c|c|c|c|c|c|c|c|c|}
\hline \multicolumn{2}{|c|}{ Follow-up } & \multicolumn{2}{|c|}{$\%$ Active ( $\geq 300 \mathrm{~min} /$ week) } & \multicolumn{2}{|c|}{ MVPA (min./week) } & \multicolumn{2}{|c|}{ Moderate-intensity PA (min./week) } & \multicolumn{2}{|c|}{ Vigorous-intensity PA (min./week) } \\
\hline \multirow[t]{3}{*}{11 years } & Total & 4293 & 48.0 & 4293 & $280(140-545)$ & 4312 & $150(75-290)$ & 4311 & $30(0-180)$ \\
\hline & Male & 2120 & 58.4 & 2120 & $370(180-662)$ & 2130 & $140(60-265)$ & 2128 & $120(16-330)$ \\
\hline & Females & 2173 & 38.0 & 2173 & $220(110-415)$ & 2182 & $167(85-315)$ & 2183 & $0(0-45)$ \\
\hline \multirow[t]{3}{*}{15 years } & Total & 4324 & 48.2 & 4324 & $280(120-580)$ & 4326 & $120(50-245)$ & 4326 & $0(0-195)$ \\
\hline & Male & 2110 & 62.6 & 2110 & $420(190-810)$ & 2115 & $100(30-200)$ & 2115 & $150(0-420)$ \\
\hline & Females & 2214 & 34.5 & 2214 & $200(90-390)$ & 2211 & $150(50-280)$ & 2211 & $0(0-0)$ \\
\hline \multirow[t]{3}{*}{18 years } & Total & 4060 & 57.3 & 4060 & $360(152-680)$ & 4104 & $240(120-490)$ & 4099 & $0(0-360)$ \\
\hline & Male & 1989 & 69.5 & 1989 & $480(250-850)$ & 2014 & $300(150-600)$ & 2010 & $120(0-600)$ \\
\hline & Females & 2071 & 45.6 & 2071 & $250(120-510)$ & 2090 & $210(90-420)$ & 2089 & $0(0-0)$ \\
\hline
\end{tabular}

MVPA Moderate to vigorous physical activity, IQR Interquartile range

as walking, gymnastics and dance whereas boys in sports practice such as soccer, basketball and handball.

Studies investigating the relation between physical activity practice and body composition showed that total physical activity, MVPA, moderate - and vigorousintensity physical activities are directly associated with free fat mass during adolescence [5]. Other studies showed that total physical activity and MVPA are associated with LM throughout adolescence [10, 11]. However, none of these studies assessed the specific associations between moderate- and vigorous-intensity physical activities and LMI.

In the present study, the assessment of the specific effects of moderate- and vigorous-intensity physical activities on LMI at 18 years old showed that boys and girls who practiced physical activity for more time at 11, 15, and 18 had higher LMI at 18 years old, except for vigorous-intensity in boys at 11 years. When the consistent practiced of MVPA, moderate- and vigorous intensity physical activity during adolescence were considered, those who reached the threshold for the referred intensities showed higher LMI levels at 18 years old, with a greater effect promoted by vigorous-intensity physical activity. It is noteworthy that most relevant effects of moderate- and vigorous physical activity practice on lean mass found for girls according to data showed in Table 3 leading to an important confounding, once that is showing crude analysis only. Additionally, in Table 4, after adjusted analysis a higher magnitude was observed for boys.

Adolescence is characterized by rapid growth with important increases in muscle mass as a natural result [1]. Nevertheless, the differences detected in adolescents who had more weekly minutes of physical activity practice and of way more consistently during this period indicate that there are physiological mechanisms in this process that are favored by physical activities, particularly vigorous ones. In this sense, the most likely explanation for the present findings is the greater stimulation of the activity of anabolic hormones such as testosterone, growth hormone, and hormonal growth factors $[31,32]$ involved in the process of increase and maintenance of LM [33-35].

The inverse effect of physical activity on BF, especially vigorous-intensity physical activity, has been shown in cross-sectional [13] and longitudinal [15] studies. In the analyses of the present study, after adjusting for a series of variables known to impact the development of $\mathrm{BF}$, only the vigorous-intensity physical activities among boys were inversely associated with FM at 18 years old. These findings match two other studies with similar methodologies as this one [36, 37].

The physiological and metabolic adaptations stimulated by physical activity practice comprising a set of mechanisms which allow the reduction of BF through metabolic demands imposed the body [38, 39]. Thus, they are pointed as the most plausible reasons for the present findings. Among other adaptations, these stand out: The higher energy expenditure $[39,40]$ required by the greater energy demand imposed by vigorous movements [41]; the higher rate of fat oxidation [42, 43], a result of the higher activity of oxidative enzymes [44, 45] and of lipolytic hormones [32, 46]; and the increased resting metabolic rate (RMR) [47, 48] through the increase in oxygen uptake after the practice of vigorousintensity physical activity [43, 49] and by the greater amount of skeletal muscle tissue $[5,10]$.

Regarding the differences identified between the sexes, the most likely reasons for not finding an inverse relation between physical activity and $B F$ in girls are: the fact that adolescence is a period of great FM acquisition for girls; the hormonal differences that are unfavorable for females in reducing FM [1]; and the lower amount of vigorous-intensity physical activity among girls throughout adolescence. The lack of sampling power to detect a statistically significant difference in favor of those who practiced vigorous- 
Table 3 Association between moderate and vigorous-intensity physical activity at 11, 15 and 18 years with body fat mass and lean mass index at 18 years in boys and girls belonging to the 1993 Pelotas (Brazil) Birth Cohort

\begin{tabular}{|c|c|c|c|c|c|c|c|c|c|c|c|c|}
\hline \multirow[t]{3}{*}{ Physical Activity Intensity in Tertiles } & \multicolumn{6}{|c|}{ Fat Mass Index (FMI) } & \multicolumn{6}{|c|}{ Lean Mass Index (LMI) } \\
\hline & \multirow[t]{2}{*}{$N$} & \multicolumn{2}{|l|}{ Boys } & \multirow[t]{2}{*}{$n$} & \multicolumn{2}{|l|}{ Girls } & \multirow[t]{2}{*}{$n$} & \multicolumn{2}{|l|}{ Boys } & \multirow[t]{2}{*}{$N$} & \multicolumn{2}{|l|}{ Girls } \\
\hline & & $\beta(95 \% \mathrm{Cl})$ & $P$ & & $\beta(95 \% \mathrm{Cl})$ & $p$ & & $\beta(95 \% \mathrm{Cl})$ & $p$ & & $\beta(95 \% \mathrm{Cl})$ & $P$ \\
\hline Moderate-intensity physical activity at $11 y$ & 1782 & & 0.7 & 1842 & & 0.3 & 1782 & & 0.003 & 1842 & & 0.005 \\
\hline 1 st & 724 & 0 & & 590 & 0 & & 724 & 0 & & 590 & 0 & \\
\hline 2nd & 548 & $-0.14(-0.48 ; 0.20)$ & & 577 & $0.00(-0.42 ; 0.40)$ & & 548 & $0.13(-0.04 ; 0.29)$ & & 577 & $0.11(-0.06 ; 0.28)$ & \\
\hline $3 r d$ & 510 & $-0.01(-0.36 ; 0.33)$ & & 675 & $0.27(-0.13 ; 0.66)$ & & 510 & $0.30(0.13 ; 0.48)$ & & 675 & $0.26(0.10 ; 0.43)$ & \\
\hline Vigorous-intensity physical activity at $11 y$ & 1780 & & 0.4 & 1843 & & 0.6 & 1780 & & 0.4 & 1843 & & 0.008 \\
\hline 1 st & 413 & 0 & & 1231 & 0 & & 413 & 0 & & 1231 & 0 & \\
\hline 2nd & 485 & $-0.07(-0.48 ; 0.33)$ & & 369 & $-0.14(-0.56 ; 0.27)$ & & 485 & $0.09(-0.11 ; 0.29)$ & & 369 & $0.06(-0.11 ; 0.23)$ & \\
\hline $3 r d$ & 882 & $-0.23(-0.59 ; 0.13)$ & & 243 & $-0.20(-0.70 ; 0.28)$ & & 882 & $0.12(-0.07 ; 0.30)$ & & 243 & $0.32(0.12 ; 0.52)$ & \\
\hline Moderate-intensity physical activity at $15 y$ & 1796 & & 0.6 & 1914 & & 0.2 & 1796 & & 0.008 & 1914 & & $<0.001$ \\
\hline 1 st & 681 & 0 & & 553 & 0 & & 681 & 0 & & 553 & 0 & \\
\hline 2nd & 609 & $-0.18(-0.51 ; 0.16)$ & & 631 & $0.18(-0.22 ; 0.59)$ & & 609 & $-0.08(-0.25 ; 0.08)$ & & 631 & $0.15(-0.01 ; 0.31)$ & \\
\hline $3 r d$ & 506 & $-0.03(-0.39 ; 0.32)$ & & 730 & $0.36(-0.03 ; 0.75)$ & & 506 & $0.20(0.02 ; 0.38)$ & & 730 & $0.31(0.15 ; 0.47)$ & \\
\hline Vigorous-intensity physical activity at $15 y$ & 1796 & & 0.001 & 1914 & & 0.2 & 1796 & & $<0.001$ & 1914 & & 0.02 \\
\hline 1 st & 436 & 0 & & 1533 & 0 & & 436 & 0 & & 1533 & 0 & \\
\hline 2nd & 390 & $-0.50(-0.92 ;-0.09)$ & & 223 & $0.07(-0.43 ; 0.57)$ & & 390 & $0.28(0.07 ; 0.49)$ & & 223 & $0.22(0.02 ; 0.42)$ & \\
\hline $3 r d$ & 970 & $-0.65(-1.00 ;-0.30)$ & & 158 & $-0.50(-1.09 ; 0.07)$ & & 970 & $0.50(0.34 ; 0.68)$ & & 158 & $0.23(0.00 ; 0.46)$ & \\
\hline Moderate-intensity physical activity at 18y & 1901 & & 0.001 & 1949 & & 0.07 & 1901 & & 0.03 & 1949 & & $<0.001$ \\
\hline 1 st & 500 & 0 & & 779 & 0 & & 500 & 0 & & 779 & 0 & \\
\hline 2nd & 642 & $-0.08(-0.43 ; 0.28)$ & & 658 & $0.27(-0.09 ; 0.64)$ & & 642 & $0.12(-0.06 ; 0.30)$ & & 658 & $0.27(0.12 ; 0.42)$ & \\
\hline $3 r d$ & 759 & $-0.56(-0.90 ;-0.21)$ & & 512 & $0.45(0.05 ; 0.84)$ & & 759 & $0.24(0.06 ; 0.41)$ & & 512 & $0.50(0.34 ; 0.66)$ & \\
\hline Vigorous-intensity physical activity at $18 y$ & 1899 & & 0.4 & 1949 & & 0.3 & 1899 & & $<0.001$ & 1949 & & $<0.001$ \\
\hline 1 st & 786 & 0 & & 1459 & 0 & & 786 & 0 & & 1459 & 0 & \\
\hline 2nd & 209 & $0.30(-0.15 ; 0.77)$ & & 101 & $0.21(-0.50 ; 0.93)$ & & 209 & $0.10(-0.13 ; 0.34)$ & & 101 & $0.36(0.07 ; 0.65)$ & \\
\hline $3 \mathrm{rd}$ & 904 & $0.10(-0.19 ; 0.39)$ & & 389 & $0.29(-0.11 ; 0.69)$ & & 904 & $0.46(0.30 ; 0.60)$ & & 389 & $0.34(0.18 ; 0.50)$ & \\
\hline
\end{tabular}

Wald test for heterogeneity 
Table 4 Association between physical activity trajectory of MVPA, moderate- and vigorous intensity at 11, 15 and 18 years with body fat and lean mass index at 18 years stratified by sex. The 1993 Pelotas (Brazil) Birth Cohort

\begin{tabular}{|c|c|c|c|c|c|c|c|c|c|c|c|c|c|}
\hline \multirow{2}{*}{\multicolumn{2}{|c|}{$\begin{array}{l}\text { Trajectories of physical activity } 11,15 \text { and } \\
18 \text { years }\end{array}$}} & \multicolumn{6}{|c|}{ Fat Mass Index (FMI) } & \multicolumn{6}{|c|}{ Lean Mass Index (LMI) } \\
\hline & & \multirow[t]{2}{*}{$n$} & \multicolumn{2}{|l|}{ Crude } & \multirow[t]{2}{*}{$n$} & \multicolumn{2}{|l|}{ Adjusted $\dagger$} & \multirow[t]{2}{*}{$n$} & \multicolumn{2}{|l|}{ Crude } & \multirow[t]{2}{*}{$n$} & \multicolumn{2}{|l|}{ Adjusted $\dagger$} \\
\hline & & & $\bar{\beta}$ coefficient $(95 \% \mathrm{Cl}$ ) & $p$ & & $\beta$ coefficient $(95 \% \mathrm{Cl}$ ) & $p$ & & $\beta$ coefficient (95 \% Cl) & $p$ & & $\beta$ coefficient $(95 \% \mathrm{Cl}$ ) & $P$ \\
\hline \multirow[t]{15}{*}{ Boys } & MVPA ( $\geq 300 \mathrm{~min} / \mathrm{wk}$ ) & 1703 & & ${ }^{*} 0.04$ & 1368 & & ${ }^{*} 0.4$ & 1703 & & $\S<0.001$ & 1368 & & $\S^{\S}<0.001$ \\
\hline & Has never reached & 113 & 0 & & 93 & 0 & & 113 & 0 & & 93 & 0 & \\
\hline & Reached once & 406 & $-0.86(-1.50 ;-0.22)$ & & 323 & $-0.42(-0.93 ; 0.08)$ & & 406 & $0.80(0.47 ; 1.14)$ & & 323 & $0.57(0.27 ; 0,87)$ & \\
\hline & Reached twice & 681 & $-0.79(-1.40 ;-0.18)$ & & 546 & $-0.35(-0.83 ; 0.13)$ & & 681 & $0.98(0.66 ; 1.30)$ & & 546 & $0.83(0.54 ; 1.12)$ & \\
\hline & Has always reached & 503 & $-0.87(-1.50 ;-0.25)$ & & 406 & $-0.26(-0.75 ; 0.24)$ & & 503 & $1.13(0.81 ; 1.46)$ & & 406 & $0.99(0.69 ; 1.29)$ & \\
\hline & $\begin{array}{l}\text { Moderate-intensity ( } \geq 150 \mathrm{~min} / \mathrm{wk}) \\
(>150 \mathrm{~min} / \text { week) }\end{array}$ & 1731 & & ${ }^{*} 0.3$ & 1386 & & $* 0.6$ & 1731 & & $\S<0.001$ & 1386 & & ${ }^{\S} 0.004$ \\
\hline & Has never reached & 180 & 0 & & 149 & 0 & & 180 & 0 & & 149 & 0 & \\
\hline & Reached once & 555 & $-0.46(-0.98 ; 0.06)$ & & 437 & $0.02(-0.38 ; 0.43)$ & & 555 & $0.23(-0.03 ; 0.49)$ & & 437 & $0.25(0.00 ; 0.50)$ & \\
\hline & Reached twice & 670 & $-0.47(-0.97 ; 0.04)$ & & 542 & $0.05(-0.35 ; 0.45)$ & & 670 & $0.29(0.04 ; 0.54)$ & & 542 & $0.29(0.05 ; 0.53)$ & \\
\hline & Has always reached & 326 & $-0.34(-0.90 ; 0.22)$ & & 258 & $0.23(-0.21 ; 0.68)$ & & 326 & $0.55(0.27 ; 0.83)$ & & 258 & $0.40(0.13 ; 0.68)$ & \\
\hline & Vigorous-intensity ( $\geq 75 \mathrm{~min} / \mathrm{wk}$ ) & 1727 & & ${ }^{*} 0.02$ & 1384 & & ${ }^{*} 0.03$ & 1727 & & $\S<0.001$ & 1384 & & $\S<0.001$ \\
\hline & Has never reached & 174 & 0 & & 134 & 0 & & 174 & 0 & & 134 & 0 & \\
\hline & Reached once & 410 & $-0.90(-1.45 ;-0.36)$ & & 323 & $-0.64(-1.08 ;-0.20)$ & & 410 & $0.48(0.20 ; 0.75)$ & & 323 & $0.53(0.27 ; 0.80)$ & \\
\hline & Reached twice & 667 & $-0.86(-1.36 ;-0.34)$ & & 536 & $-0.54(-0.95 ;-0.13)$ & & 667 & $0.54(0.28 ; 0.80)$ & & 536 & $0.62(0.37 ; 0.87)$ & \\
\hline & Has always reached & 476 & $-0.74(-1.27 ;-0.20)$ & & 391 & $-0.53(-0.96 ;-0.10)$ & & 476 & $0.88(0.62 ; 1.15)$ & & 391 & $0.95(0.69 ; 1.21)$ & \\
\hline \multirow[t]{10}{*}{ Girls } & MVPA ( $\geq 300 \mathrm{~min} / \mathrm{wk}$ ) & 1797 & & ${ }^{*} 0.1$ & 1576 & & $* 0.3$ & 1797 & & ${ }^{*}<0.001$ & 1576 & & ${ }^{*}<0.001$ \\
\hline & Has never reached & 467 & 0 & & 405 & 0 & & 467 & 0 & & 405 & 0 & \\
\hline & Reached once & 683 & $0.47(0.05 ; 0.89)$ & & 597 & $0.20(-0.10 ; 0.50)$ & & 683 & $0.24(0.07 ; 0.41)$ & & 597 & $0.13(-0.02 ; 0.28)$ & \\
\hline & Reached twice & 499 & $0.45(0.00 ; 0.90)$ & & 441 & $0.19(-0.13 ; 0.52)$ & & 499 & $0.51(0.33 ; 0.70)$ & & 441 & $0.34(0.18 ; 0.50)$ & \\
\hline & Has always reached & 148 & $0.37(-0.29 ; 1.03)$ & & 133 & $-0.13(-0.61 ; 0.34)$ & & 148 & $0.49(0.22 ; 0.76)$ & & 133 & $0.23(-0.00 ; 0.47)$ & \\
\hline & Moderate-intensity ( $\geq 150 \mathrm{~min} / \mathrm{wk}$ ) & 1820 & & ${ }^{*} 0.1$ & 1594 & & *0.9 & 1820 & & ${ }^{*}<0.001$ & 1594 & & ${ }^{*} 0.006$ \\
\hline & Has never reached & 205 & 0 & & 176 & 0 & & 205 & 0 & & 176 & 0 & \\
\hline & Reached once & 522 & $0.30(-0.27 ; 0.88)$ & & 457 & $0.02(-0.39 ; 0.44)$ & & 522 & $0.21(-0.02 ; 0.45)$ & & 457 & $0.16(-0.04 ; 0.37)$ & \\
\hline & Reached twice & 661 & $0.43(-0.13 ; 0.99)$ & & 580 & $0.07(-0.33 ; 0.48)$ & & 661 & $0.51(0.28 ; 0.74)$ & & 580 & $0.34(0.13 ; 0.54)$ & \\
\hline & Has always reached & 432 & $0.68(0.08 ; 1.28)$ & & 381 & $-0.05(-0.48 ; 0.38)$ & & 432 & $0.50(0.26 ; 0.74)$ & & 381 & $0.23(0.02 ; 0.45)$ & \\
\hline
\end{tabular}


Table 4 Association between physical activity trajectory of MVPA, moderate- and vigorous intensity at 11, 15 and 18 years with body fat and lean mass index at 18 years stratified by sex. The 1993 Pelotas (Brazil) Birth Cohort (Continued)

\begin{tabular}{|c|c|c|c|c|c|c|c|c|c|c|c|c|}
\hline Vigorous-intensity ( $\geq 75 \mathrm{~min} / \mathrm{wk}$ ) & 1821 & & ${ }^{*} 0.7$ & 1595 & & ${ }^{*} 0.3$ & 1821 & & $\S<0.001$ & 1595 & & $\S<0.001$ \\
\hline Has never reached & 1014 & 0 & & 873 & 0 & & 1014 & 0 & & 873 & 0 & \\
\hline Reached once & 618 & $-0.02(-0.38 ; 0.33)$ & & 549 & $-0.04(-0.29 ; 0.22)$ & & 618 & $0.26(0.12 ; 0.40)$ & & 549 & $0.27(0.14 ; 0.39)$ & \\
\hline Reached twice & 165 & $-0.32(-0.91 ; 0.27)$ & & 152 & $0.04(-0.37 ; 0.45)$ & & 165 & $0.28(0.04 ; 0.52)$ & & 152 & $0.35(0.14 ; 0.56)$ & \\
\hline Has always reached & 24 & $-0.24(-1.69 ; 1.21)$ & & 21 & $-0.94(-1.97 ; 0.09)$ & & 24 & $1.04(0.46 ; 1.63)$ & & 21 & $0.80(0.29 ; 1.32)$ & \\
\hline
\end{tabular}

* $P$ value of heterogeneity; $\S P$ value for trend; $\dagger$ Adjusted for: Asset index, skin color, medicine use for weight loss, weight loss diet, fat intake, BMI, screen time (hours/week) and adolescent schooling at 11 years, physical activity mother and mother's BMl, collected at 11 years and sexual maturation (Tanner stages/pubic hair) collected at 15 year

Has never reached, Reached once, Reached twice and Has always reached = times that reach the thresholds of the $\geq 300$ ( $\mathrm{min} / \mathrm{wk}$ ), $\geq 150$ ( $\mathrm{min} / \mathrm{wk}$ ) and $\geq 75$ (min/wk) for MVPA, moderate- and vigorous intensity physical activity, respectively, to 11,15 and 18 years 


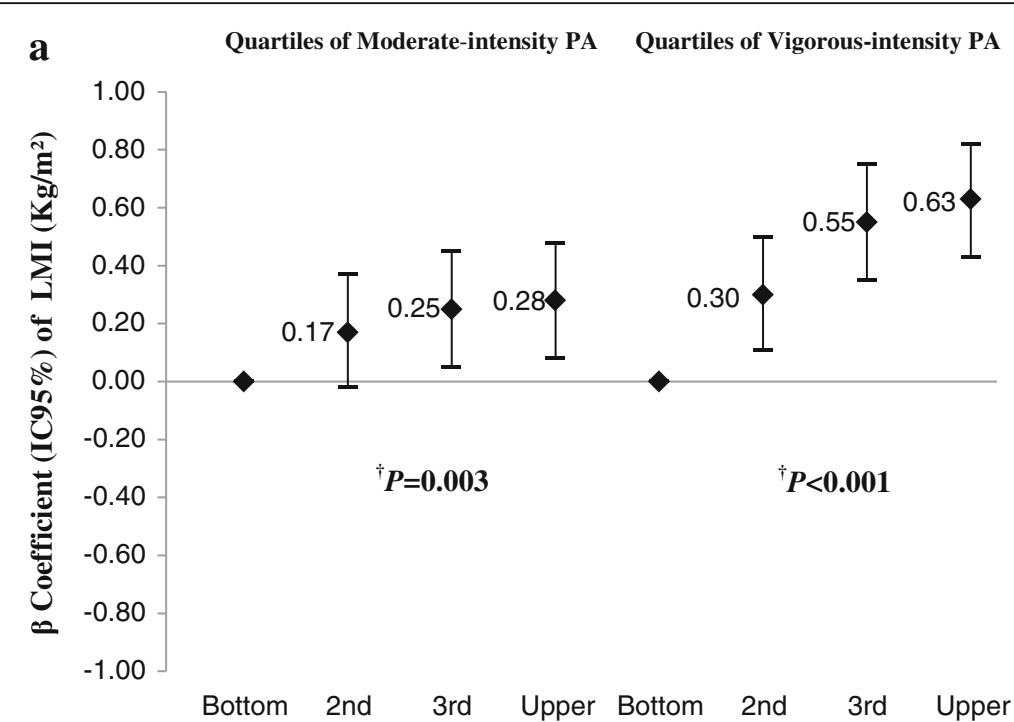

b

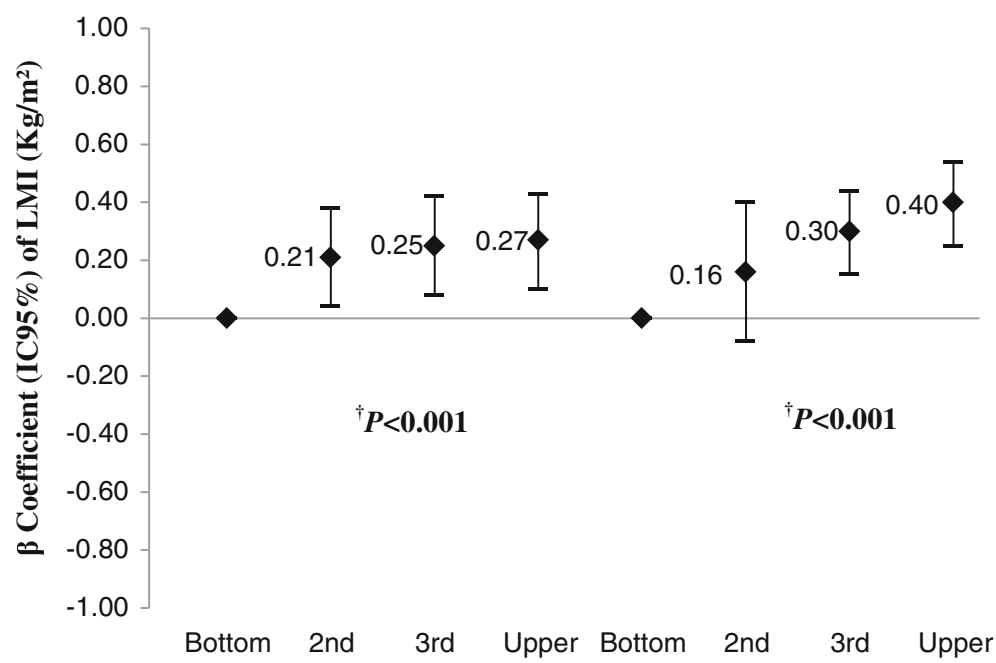

Fig. 1 *Adjusted for: Asset index, skin color, medications for weight loss, weight loss diet, fat intake, BMl, screen time (hours/week) and adolescent education, physical activity mother and mother's BMI, collected at 11 years and sexual maturation (Tanner stages/pubic hair) collected at 15 year; $+P$ value of tendency; $F M I=$ Fat mass index; $L M I=$ Lean mass index. Effect of moderate- and vigorous-intensity physical activity accumulated at 11, 15 and 18 years on LMI in boys (a) and girls (b) belonging to the 1993 Pelotas (Brasil) Birth Cohort

intensity physical activity for $75 \mathrm{~min} /$ week or more at the 3 ages assessed must also be considered. Furthermore, during adolescence, boys have a great capacity of oxidizing fat [50].

It is important to highlight that physical activity and caloric intake are the main elements in the energetic balance and both are important in body composition changes especially in maintaining weight and preventing weight and body fat gain [51]. Experimental studies state that when diet and physical activities are administrated together, they promote stronger effects on body composition $[12,52,53]$. In order to reduce weight and body fat, a negative energetic balance as a result from consumed energy and spent energy is expected. Therefore, if the caloric intake is higher than energetic expenditure, the effects of physical activity may not be observed [54]. In this study, it was not possible to observe the effect of a higher amount of physical activity on body fat in some associations which may be the result of a positive energetic balance. However, it is important to highlight that although we do not have measures for caloric intakes, our analysis were adjusted for diets with high consumption of fat possibly indicating a diet with high calories. Therefore, we believe that the lack of association between physical activity practice and a lower amount of body fat is mainly due to the low amount of vigorous activity and the lack of sample power in some categories. 
Some important issues can be considered limitations in the present study. The practice of physical activity at 11,15 , and 18 years old was measured through questionnaires, which allows for classification errors inherent to the instruments such as over or underestimated answers. However, the instrument used at 11 and 15 years old has been used in several follow-ups with participants of Pelotas birth cohorts (1982, 1993 and 2004) [30], also in cross-sectional surveys with adolescents of Pelotas city $[29,55]$. Additionally, it shows good reliability and allows a wide description of commuting and leisure time physical activity [55]. At 18 years old, the IPAQ questionnaire was used, an instrument validated by using accelerometers as criterion method and that has been widely used in studies with large samples [56, 57]. The fact that two different instruments were used to measure physical activity at 11 and 15 and at 18 years old can be minimized since only leisure and commuting activities were considered, which were standardized and expressed as MVPA, moderate, and vigorous physical activity with the same thresholds applied to all periods. In addition, the moderate- and vigorous-intensity physical activities were classified based on the specific compendium for adolescents [22] and on the guideline for processing and analyzing IPAQ data [20]. Other condition that could be considered as a limitation of study was the fact that physical activities of light intensity as well as the domestic and occupational were not included as variables. However, the main goal of this study was regarded to the relationships between MVPA, moderate- and vigorous intensities physical activity. Furthermore, the used instruments to measure physical activity are less suitable to measures light, domestics and occupational physical activity. In addition, the lack of sample power in many categories was responsible for the weak or no association found in several analyses.

Among the strengths of the present study, the following aspects stand out: (i) The 3 measurements of physical activity during adolescence representing the ages at the beginning ( 11 years old), middle ( 15 years old), and end (18 years old) of this phase allowed assessing the change over the period and to plot trajectories; (ii) using DXA allowed FM and LM to be specifically measured; (iii) the outcomes of FM and LM were adjusted for the height of the subjects by transforming the absolute FM and LM measures into indices (FMI and LMI); (iv) the analyses were adjusted for a series of variables known to affect the development of FM and LM; and (v) being a population cohort study carried out in Brazil.

\section{Conclusions}

In summary, maintaining high levels of physical activity practice during adolescence, particularly vigorous-intensity activity was related to greater LM levels in both sexes and to a lower FM level among 18-year-old boys. Even if physical activity practice did not have direct relationship on FM levels among girls, the effect of vigorous-intensity physical activity on LM gain suggests that this may be an important strategy to increase energy expenditure and RMR, besides aiding in maintaining or reducing $\mathrm{BF}$.

Thus, the results suggest that accumulating $75 \mathrm{~min} /$ week or more of vigorous-intensity physical activity throughout adolescence seems appropriate to promote changes in body composition of boys and girls and, hence, is able to aid in fighting the overweight and obesity epidemic.

\section{Acknowledgements}

The authors would like to thank the adolescents and staff who participated in research.

\section{Findings}

This article is based on data from the study "Pelotas Birth Cohort, 1993" conducted by Postgraduate Program in Epidemiology at Universidade Federal de Pelotas. The 1993 birth cohort study is currently supported by the Wellcome Trust through the program entitled Major Awards for Latin America on Health Consequences of Population Change. The European Union, National Support Program for Centers of Excellence (PRONEX), the Brazilian National Research Council (CNPq), and the Brazilian Ministry of Health supported previous phases of the study. The funding bodies did not contribute to the design of the study, data collection, analysis or interpretation of data.

\section{Availability of data and material}

The dataset supporting of this article are available upon request to the corresponding author.

\section{Authors' contributions}

WR led the analysis and wrote this paper. SCD and FCW collaborated in the analysis process and critical revision of the manuscript. $\mathrm{HG}, \mathrm{PCH}$ and $\mathrm{AMB}$ collaborated with the critical revision of the manuscript. All authors read and approved the final version of the manuscript.

\section{Competing interests}

The authors declare that they have no competing interest.

Consent for publication

Not applicable.

\section{Ethics approval and consent to participate}

All data collection was approved by the Research Ethics Committee of the Medical School of the Federal University of Pelotas and all legal guardians or the subjects themselves when over 18 - signed the Term of Free and Informed Consent.

\section{Author details \\ ${ }^{1}$ Graduate Program in Epidemiology, Federal University of Pelotas, Marechal Deodoro, 1160 - 3 Piso, 96020-220 Pelotas, Rio Grande do Sul, Brazil. ${ }^{2}$ Graduate Program in Public Health, Federal University of Rio Grande, Rio Grande, Brazil.}

Received: 18 March 2016 Accepted: 21 September 2016 Published online: 01 October 2016

\section{References}

1. Rogol AD, Roemmich JN, Clark PA. Growth at puberty. J Adolesc Health. 2002;31(6 Suppl):192-200.

2. Viner RM, Cole TJ. Who changes body mass between adolescence and adulthood? Factors predicting change in BMl between 16 year and 30 years in the 1970 British Birth Cohort. Int J Obes (Lond). 2006;30(9):1368-74. doi:10.1038/sj.ijo.0803183. 
3. Baker JL, Olsen LW, Sorensen TI. Childhood body-mass index and the risk of coronary heart disease in adulthood. N Engl J Med. 2007;357(23):2329-37. doi:10.1056/NEJMoa072515.

4. Bielemann RM, Domingues MR, Horta BL, Menezes AM, Goncalves $\mathrm{H}$, Assuncao MC, et al. Physical activity throughout adolescence and bone mineral density in early adulthood: the 1993 Pelotas (Brazil) Birth Cohort Study. Osteoporos Int. 2014;25(8):2007-15. doi:10.1007/s00198-014-2715-4.

5. Jimenez-Pavon D, Fernandez-Vazquez A, Alexy U, Pedrero R, Cuenca-Garcia M, Polito A, et al. Association of objectively measured physical activity with body components in European adolescents. BMC Public Health. 2013;13(1):667. doi:10.1186/1471-2458-13-667.

6. Riddoch CJ, Leary SD, Ness AR, Blair SN, Deere K, Mattocks C, et al. Prospective associations between objective measures of physical activity and fat mass in 12-14 year old children: the Avon Longitudinal Study of Parents and Children (ALSPAC). BMJ. 2009;339:b4544.

7. Dumith SC, Gigante DP, Domingues MR, Kohl HW. 3rd. Physical activity change during adolescence: a systematic review and a pooled analysis. Int J Epidemiol. 2011;40(3):685-98. doi:10.1093/ije/dyq272.

8. Bielemann RM, Martinez-Mesa J, Gigante DP. Physical activity during life course and bone mass: a systematic review of methods and findings from cohort studies with young adults. BMC Musculoskelet Disord. 2013;14:77. doi:10.1186/1471-2474-14-771471-2474-14-77.

9. Ramires W, Dumith SC, Goncalves H. Longitudinal association between physical activity and body fat during adolescence: a systematic review. J Phys Act Health. 2015;12:1344-58. doi:10.1123/jpah.2014-0222.

10. Baxter-Jones AD, Eisenmann JC, Mirwald RL, Faulkner RA, Bailey DA. The influence of physical activity on lean mass accrual during adolescence: a longitudinal analysis. J Appl Physiol (1985). 2008;105(2):734-41. doi:10.1152/japplphysiol.00869.200700869.2007.

11. Ness AR, Leary SD, Mattocks C, Blair SN, Reilly JJ, Wells J, et al. Objectively measured physical activity and fat mass in a large cohort of children. PLoS Med. 2007:4(3):e97. doi:10.1371/journal.pmed.0040097.

12. Jakicic JM, Otto AD. Physical activity considerations for the treatment and prevention of obesity. Am J Clin Nutr. 2005;82(1 Suppl):226S-9S.

13. Hay J, Maximova K, Durksen A, Carson V, Rinaldi RL, Torrance B, et al. Physical activity intensity and cardiometabolic risk in youth. Arch Pediatr Adolesc Med 2012;166(11):1022-9. doi:10.1001/archpediatrics.2012.10281357758.

14. Martinez-Gomez D, Ruiz JR, Ortega FB, Veiga OL, Moliner-Urdiales D, Mauro $B$, et al. Recommended levels of physical activity to avoid an excess of body fat in European adolescents: the HELENA Study. Am J Prev Med. 2010;39(3):203-11. doi:10.1016/j.amepre.2010.05.00350749-3797(10)00345-4.

15. Cohen DA, Ghosh-Dastidar B, Conway TL, Evenson KR, Rodriguez DA, Beckman $\mathrm{R}$, et al. Energy balance in adolescent girls: the trial of activity for adolescent girls cohort. Obesity (Silver Spring). 2014;22(3):772-80. doi:10.1002/oby.20536.

16. Carson V, Rinaldi RL, Torrance B, Maximova K, Ball GD, Majumdar SR, et al. Vigorous physical activity and longitudinal associations with cardiometabolic risk factors in youth. Int J Obes (Lond). 2014;38(1):16-21. doi:10.1038/ijo.2013.135.

17. Victora CG, Hallal PC, Araujo CL, Menezes AM, Wells JC, Barros FC. Cohort profile: the 1993 Pelotas (Brazil) birth cohort study. Int J Epidemiol. 2008;37(4):704-9. doi:10.1093/ije/dym177.

18. Goncalves H, Assuncao MC, Wehrmeister FC, Oliveira IO, Barros FC, Victora CG, et al. Cohort profile update: The 1993 Pelotas (Brazil) Birth Cohort follow-up visits in adolescence. Int J Epidemiol. 2014;43(4):1082-8. doi:10.1093/ije/dyu077dyu077.

19. Vanltallie TB, Yang MU, Heymsfield SB, Funk RC, Boileau RA. Heightnormalized indices of the body's fat-free mass and fat mass: potentially useful indicators of nutritional status. Am J Clin Nutr. 1990;52(6):953-9.

20. Guidelines for Data Processing and Analysis of the International Physical Activity Questionnaire (IPAQ) - Short Form, version 2.0. April 2004.

21. Pate RR, Pratt M, Blair SN, Haskell WL, Macera CA, Bouchard C, et al. Physical activity and public health. A recommendation from the Centers for Disease Control and Prevention and the American College of Sports Medicine. JAMA. 1995;273(5):402-7.

22. Ridley K, Ainsworth BE, Olds TS. Development of a compendium of energy expenditures for youth. Int J Behav Nutr Phys Act. 2008;5:45. doi:10.1186/1479-5868-5-451479-5868-5-45

23. Ainsworth BE, Haskell WL, Leon AS, Jacobs Jr DR, Montoye HJ, Sallis JF, et al. Compendium of physical activities: classification of energy costs of human physical activities. Med Sci Sports Exerc. 1993;25(1):71-80.
24. Physical Activity Guidelines Advisory Committee. Physical activity guidelines advisory committee report, 2008. Washington, DC: U.S: Department of Health and Human Services; 2008.

25. Barros AJ, Victora CG. [A nationwide wealth score based on the 2000 Brazilian demographic census]. Rev Saude Publica. 2005;39(4):523-9.

26. Block $G$, Gillespie $C$, Rosenbaum EH, Jenson C. A rapid food screener to assess fat and fruit and vegetable intake. Am J Prev Med. 2000;18(4):284-8.

27. Tanner JM. Fetus into Man: Physical Growth from Conception to Maturity. Harvard University Press; 1990

28. Wells JC. Sexual dimorphism of body composition. Best Pract Res Clin Endocrinol Metab. 2007;21(3):415-30. doi:10.1016/j.beem.2007.04.007.

29. Coll Cde V, Knuth AG, Bastos JP, Hallal PC, Bertoldi AD. Time trends of physical activity among Brazilian adolescents over a 7-year period. J Adolesc Health. 2014;54(2):209-13. doi:10.1016/j.jadohealth.2013.08.010.

30. Dumith SC, Gigante DP, Domingues MR, Hallal PC, Menezes AM, Kohl 3rd HW. A longitudinal evaluation of physical activity in Brazilian adolescents: tracking, change and predictors. Pediatr Exerc Sci. 2012;24(1):58-71.

31. Cadore EL, Izquierdo M, dos Santos MG, Martins JB, Rodrigues Lhullier FL, Pinto RS, et al. Hormonal responses to concurrent strength and endurance training with different exercise orders. J Strength Cond Res. 2012;26(12):3281-8. doi:10.1519/JSC.0b013e318248ab26.

32. Consitt LA, Copeland JL, Tremblay MS. Endogenous anabolic hormone responses to endurance versus resistance exercise and training in women. Sports Med. 2002;32(1):1-22.

33. Clemmons DR. Role of IGF-I in skeletal muscle mass maintenance. Trends Endocrinol Metab. 2009;20(7):349-56. doi:10.1016/j.tem.2009.04.002S10432760(09)00090-3.

34. Meinhardt U, Nelson AE, Hansen JL, Birzniece V, Clifford D, Leung KC, et al. The effects of growth hormone on body composition and physical performance in recreational athletes: a randomized trial. Ann Intern Med. 2010;152(9):568-77. doi:10.7326/0003-4819-152-9-201005040-00007152/9/568.

35. Sinha-Hikim I, Artaza J, Woodhouse L, Gonzalez-Cadavid N, Singh AB, Lee $\mathrm{Ml}$, et al. Testosterone-induced increase in muscle size in healthy young men is associated with muscle fiber hypertrophy. Am J Physiol Endocrinol Metab. 2002;283(1):E154-64. doi:10.1152/ajpendo.00502.2001.

36. Martinez-Gomez D, Mielke Gl, Menezes AM, Goncalves H, Barros FC, Hallal PC. Active commuting throughout adolescence and central fatness before adulthood: prospective birth cohort study. PLOS ONE. 2014;9(5):e96634. doi:10.1371/journal.pone.0096634.

37. Mundt CA, Baxter-Jones AD, Whiting SJ, Bailey DA, Faulkner RA, Mirwald RL. Relationships of activity and sugar drink intake on fat mass development in youths. Med Sci Sports Exerc. 2006;38(7):1245-54. doi:10.1249/01.mss. 0000227309.18902.fe00005768-200607000-00008.

38. Gutin B, Yin Z, Humphries MC, Barbeau P. Relations of moderate and vigorous physical activity to fitness and fatness in adolescents. Am J Clin Nutr. 2005;81(4):746-50

39. Yoshioka M, Doucet E, St-Pierre S, Almeras N, Richard D, Labrie A, et al. Impact of high-intensity exercise on energy expenditure, lipid oxidation and body fatness. Int J Obes Relat Metab Disord. 2001;25(3):332-9. doi:10.1038/sj.ijo.0801554.

40. Speakman JR, Selman C. Physical activity and resting metabolic rate. Proc Nutr Soc. 2003;62(3):621-34. doi:10.1079/PNS2003282S0029665103000855.

41. Howley ET. Type of activity: resistance, aerobic and leisure versus occupational physical activity. Med Sci Sports Exerc. 2001;33(6 Suppl):S364-9. discussion S419-20.

42. Horowitz JF. Fatty acid mobilization from adipose tissue during exercise. Trends Endocrinol Metab. 2003;14(8):386-92.

43. Spriet LL. Regulation of skeletal muscle fat oxidation during exercise in humans. Med Sci Sports Exerc. 2002;34(9):1477-84. doi:10.1249/01.MSS. 0000027688.49712.5B

44. Little JP, Safdar A, Wilkin GP, Tarnopolsky MA, Gibala MJ. A practical model of low-volume high-intensity interval training induces mitochondrial biogenesis in human skeletal muscle: potential mechanisms. J Physiol. 2010; 588(Pt 6):1011-22. doi:10.1113/jphysiol.2009.181743jphysiol.2009.181743.

45. Talanian JL, Holloway GP, Snook LA, Heigenhauser GJ, Bonen A, Spriet LL. Exercise training increases sarcolemmal and mitochondrial fatty acid transport proteins in human skeletal muscle. Am J Physiol Endocrinol Metab. 2010; 299(2):E180-8. doi:10.1152/ajpendo.00073.2010ajpendo.00073.2010.

46. Watt MJ, Spriet LL. Regulation and role of hormone-sensitive lipase activity in human skeletal muscle. Proc Nutr Soc. 2004;63(2):315-22. doi:10.1079/PNS2004360S0029665104000424 
47. Hunter GR, Weinsier RL, Bamman MM, Larson DE. A role for high intensity exercise on energy balance and weight control. Int J Obes Relat Metab Disord. 1998;22(6):489-93.

48. Stiegler P, Cunliffe A. The role of diet and exercise for the maintenance of fat-free mass and resting metabolic rate during weight loss. Sports Med. 2006;36(3):239-62.

49. Gore CJ, Withers RT. Effect of exercise intensity and duration on postexercise metabolism. J Appl Physiol (1985). 1990;68(6):2362-8.

50. Riddell MC, Jamnik VK, Iscoe KE, Timmons BW, Gledhill N. Fat oxidation rate and the exercise intensity that elicits maximal fat oxidation decreases with pubertal status in young male subjects. J Appl Physiol (1985). 2008:105(2): 742-8. doi:10.1152/japplphysiol.01256.200701256.2007.

51. Pate RR, O'Neill JR, Liese AD, Janz KF, Granberg EM, Colabianchi N, et al. Factors associated with development of excessive fatness in children and adolescents: a review of prospective studies. Obes Rev. 2013:14(8):645-58. doi:10.1111/obr.12035.

52. Benito PJ, Bermejo LM, Peinado AB, Lopez-Plaza B, Cupeiro R, Szendrei B, et al. Change in weight and body composition in obese subjects following a hypocaloric diet plus different training programs or physical activity recommendations. J Appl Physiol (1985). 2015;118(8):1006-13. doi:10.1152/japplphysiol.00928.2014.

53. Watts $K$, Jones TW, Davis EA, Green D. Exercise training in obese children and adolescents: current concepts. Sports Med. 2005;35(5):375-92.

54. Blair SN, LaMonte MJ, Nichaman MZ. The evolution of physical activity recommendations: how much is enough? Am J Clin Nutr. 2004;79(5):913S-20S

55. Bastos JP, Araujo CL, Hallal PC. Prevalence of insufficient physical activity and associated factors in Brazilian adolescents. J Phys Act Health. 2008:5(6):777-94.

56. Craig CL, Marshall AL, Sjostrom M, Bauman AE, Booth ML, Ainsworth BE, et al. International physical activity questionnaire: 12-country reliability and validity. Med Sci Sports Exerc. 2003;35(8):1381-95. doi:10.1249/01.MSS 0000078924.61453.FB.

57. Matsudo S, Araujo T, Matsudo V, Andrade D, Andrade E, Oliveira LC, et al. International Physical Activity Questionnaire (IPAQ): study of validity and reliability in Brazil. Braz J Phys Activity Health. 2001;6(2):5-18. doi:10.12820/ rbafs.v.6n2p5-18.

\section{Submit your next manuscript to BioMed Central and we will help you at every step:}

- We accept pre-submission inquiries

- Our selector tool helps you to find the most relevant journal

- We provide round the clock customer support

- Convenient online submission

- Thorough peer review

- Inclusion in PubMed and all major indexing services

- Maximum visibility for your research

Submit your manuscript at www.biomedcentral.com/submit

) Biomed Central 